\title{
Os mortos e feridos na "guerra às drogas": uma crítica ao paradigma proibicionista
}

\author{
The dead and wounded in the "war on drugs": A \\ criticism of the prohibitionist paradigm
}

\author{
Larissa Nadine RYBKA $^{1}$ \\ ORCID iD 0000-0001-7231-8374 \\ Juliana Luporini do NASCIMENTO2 \\ ORCID iD 0000-0002-8420-1672 \\ Raquel Souza Lobo GUZZO3 \\ ORCID iD 0000-0002-7029-2913
}

\begin{abstract}
Resumo
A crítica ao proibicionismo, paradigma de política de drogas globalmente hegemônico, tem como ponto de partida a emergência da própria "questão das drogas", em âmbito internacional, há aproximadamente um século. As motivações, as estratégias e os desdobramentos desse paradigma serão analisados em torno dos dois eixos que o constituem: a medicalização e a criminalização (ambos associados a questões morais profundamente arraigadas nas sociedades que 0 adotaram. O presente artigo se deterá nas particularidades do processo brasileiro, desde a implantação do proibicionismo, no início do século XX, até a sua configuração atual de "guerra às drogas", engendrada nos anos 1960. Nessa trajetória, a partir dos anos 1970, vozes dissonantes oriundas de diversos campos de conhecimento e de ação política têm se erguido. A explicitação dos objetivos não declarados da "guerra às drogas" (que a tornam, afinal, vitoriosa) e a construção de políticas públicas alternativas por esses atores têm gerado tensões e fissuras importantes na política de drogas vigente.
\end{abstract}

Palavras-chave: Crime; Direitos humanos; Drogas; Medicalização.

\begin{abstract}
The starting point of the criticism of prohibitionism, the global hegemonic paradigm of drug policies, was the emergency of the concept of "drugs" itself in an international level approximately a century ago. The motivations, strategies, and developments of this paradigm will be analyzed considering its two pillars: medicalization and criminalization (both
\end{abstract}

1 Universidade Estadual de Campinas, Faculdade de Ciências Médicas, Laboratório de Estudos Interdisciplinares sobre Psicoativos. Campinas, SP, Brasil.

2 Universidade Estadual de Campinas, Faculdade de Ciências Médicas, Departamento de Saúde Coletiva. R. Tessália Vieira de Camargo, 126, Cidade Universitária Zeferino Vaz, 13083-887, Campinas, SP, Brasil. Correspondência para/Correspondence to: J.L. NASCIMENTO. E-mail:<jluporini10@hotmail.com>.

3 Pontifícia Universidade Católica de Campinas, Centro de Ciências da Vida, Faculdade de Psicologia. Campinas, SP, Brasil. Artigo elaborado a partir da dissertação de L.N. RYBKA, intitulada "A dialética resistência/entrega no uso nocivo de substâncias psicoativas por mulheres”. Universidade Estadual de Campinas, 2015.

$\boldsymbol{\nabla} \mathbf{V} \mathbf{v}$

Como citar este artigo/How to cite this article

Rybka, L. N., Nascimento, J. L., \& Guzzo, R. S. L. (2018). Os mortos e feridos na "Guerra às Drogas": uma crítica ao paradigma proibicionista. Estudos de Psicologia (Campinas), 35(1), 99-109. https://doi.org/10.1590/1982-027520180001000010 
associated with the moral issues deeply rooted in the societies that have adopted it). The present study focuses on the particularities of the Brazilian process, starting from the implementation of prohibitionism in the early twentieth century to the current "war on drugs", which was launched in the 1960s. Over the course of time, from the 1970s onwards, dissonant voices from different fields of knowledge and political action have been raised. The unveil of the undeclared objectives of the "war on drugs" (which have made this war victorious after all) and the development of alternative public policies by these actors have generated important tensions and created gaps in the current drug policy.

Keywords: Crime; Human rights; Drugs; Medicalization.

\section{O paradigma proibicionista}

As drogas emergiram como questão a ser tratada publicamente na virada do século XIX para o XX, ou seja, trata-se de uma problemática recente se for considerado que, ao longo de toda a História, a humanidade fez uso de Substâncias Psicoativas (SPA) com diversas finalidades (Escohotado, 1998). Na interação SPA-sujeito-contexto social, ocorrem alterações do humor, da percepção, do pensamento e do comportamento, buscadas para fins recreativos, místico-religiosos e medicinais. Segundo MacRae (s.d.):

Uma das razões pelas quais durante a maior parte da história o uso de drogas não apresentasse maiores ameaças à sociedade constituída é que ele geralmente se dava no bojo de rituais coletivos ou orientado por objetivos que a sociedade reconhecia como expressão de seus próprios valores (p.1).

Esse quadro começou a mudar a partir do século XVI, quando, com as Grandes Navegações, os europeus entraram em contato com uma diversidade de produtos, entre eles as SPA. O caráter de resistência cultural ao processo de colonização assumido por algumas dessas substâncias fez com que, inicialmente, seu uso pelos povos nativos fosse violentamente reprimido pelos colonizadores, como foi o caso do ópio na Ásia e da folha de coca na América Latina (Escohotado, 1998). No entanto, as metrópoles não tardaram a perceber que alguma tolerância em relação ao uso das SPA era estratégica para a dominação dos povos colonizados e que, além disso, o comércio das mesmas poderia ser bastante lucrativo. Assim, diversas SPA originárias das colônias foram progressivamente introduzidas
Com o desenvolvimento e a expansão global do capitalismo, paulatinamente, as SPA se converteram em mercadorias, o que alterou todo o seu processo de produção, distribuição e consumo. Silva (2011) considera como marco histórico deste processo de mercantilização as Guerras do Ópio (1839 e 1865). Em nome do "livre comércio", a Inglaterra declarou guerra à China e com isso garantiu o monopólio internacional sobre a distribuição de ópio, consolidou seu domínio no Extremo Oriente e inaugurou a prática do comércio de substâncias psicoativas em larga escala.

A partir de então, houve a popularização do consumo desses produtos no contexto sociocultural de cada nação - desprovido de qualquer 'lastro cultural' que funcionasse como mecanismo de controle informal do consumo -, o que acarretou uma série de desdobramentos e impactos sociais, tais como relatos de overdoses, complicações crônicas à saúde e o desmantelamento de hábitos sociais locais tradicionalmente instituídos (Silva, 2011, p.1).

Ainda no século XIX, com o avanço do conhecimento científico, substâncias como a heroína e a cocaína foram isoladas quimicamente, permitindo sua produção em laboratório em concentrações muito superiores às encontradas nas plantas cultivadas por milênios em seus territórios de origem. Além das SPA já conhecidas e consumidas, inúmeras novas substâncias passaram a ser sintetizadas em laboratório, abrindo um mercado muito promissor. O interesse econômico em torno das SPA evidencia-se no crescimento vertiginoso dos valores movimentados em seu comércio ao longo do século $X X$ tanto pelo tráfico internacional de 
drogas ${ }^{4}$ quanto pela produção e venda legal de medicamentos psicotrópicos através da indústria farmacêutica ${ }^{5}$. Se o primeiro se beneficia de taxas de lucro que somente podem ser obtidas na condição de ilegalidade, a última conquistou o monopólio da produção e do comércio de grande parte das drogas legais (em um processo contínuo de desenvolvimento de novos produtos, legitimado pela ciência).

Certamente, a motivação econômica foi fundamental para o desenvolvimento do paradigma proibicionista no início do século $X X$ e para $O$ interesse em sua manutenção até os dias atuais, a despeito de seus efeitos desastrosos (principalmente sobre as classes sociais mais desfavorecidas). No entanto, os ganhos econômicos diretos por si só não explicam a opção por esse modelo; não explicam, por exemplo, o critério de classificação das SPA em lícitas e ilícitas - critério que, obviamente, não se justifica pelos efeitos supostamente mais danosos das últimas, como quer fazer crer o discurso oficial. Essa argumentação não resiste aos dados mais elementares de saúde pública (nacionais e internacionais), nos quais o álcool aparece em primeiro lugar como causa de morbimortalidade pelo uso de SPA, seguido pelo tabaco (Duarte, Stempliuk, \& Barroso, 2009).

De fato, para além do "bom negócio" que representam tanto o mercado legal quanto o ilegal de substâncias psicoativas, a política de drogas vigente cumpre com outro objetivo estratégico para a reprodução do capital: trata-se do controle social necessário ao estabelecimento de uma ordem social geradora das mais diversas formas de violência, injustiça e opressão. A estigmatização e a criminalização de determinadas SPA em determinados contextos sociais de uso tem sido, há aproximadamente cem anos, uma poderosa ferramenta de desqualificação de grupos sociais específicos e de autorização para a execução das mais diversas formas de violência contra os mesmos. Segundo Karam (2009), a tolerância ou a repressão ao uso de determinadas SPA em uma sociedade estão relacionadas à inscrição desse uso em rituais coletivos que expressam valores sociais dominantes ou, pelo contrário, à circunstâncias de uso as quais constituem uma ameaça à ordem social estabelecida. De forma sintética, é possível dizer que os discursos e as práticas sociais que sustentam o paradigma proibicionista estão organizados em torno de dois eixos: a medicalização e a criminalização, ambos associados a questões morais profundamente arraigadas nas sociedades que adotaram o paradigma.

\section{A medicalização e a criminalização das drogas enquanto sustentáculos do proibicionismo}

Ao longo do século XIX, a medicina passou por um processo complexo de adequação aos parâmetros da racionalidade desde então hegemônica na ciência ocidental moderna, de base positivista. A legitimidade científica e social alcançada ao final desse processo propiciou sua transformação em um instrumento de grande interesse para a consolidação do capitalismo (Donnangelo, 1975). Os saberes médicos assim concebidos são particularmente estratégicos para o disciplinamento e controle (individual e social), por permitirem uma intervenção direta sobre os corpos e a organização da vida cotidiana. A história da Medicina Social e da Clínica Médica é repleta de exemplos de instrumentalização de seus saberes (que foram deslocando e deslegitimando outros) para o controle dos processos humanos vitais.

Durante o século $X X$, a normatividade médica estendeu-se progressivamente para toda a vida social, definindo os limites entre o normal e o patológico, classificando e hierarquizando os seres humanos em todas as práticas que o constituem (trabalho, reprodução/sexualidade, higiene, ali-

$\boldsymbol{\nabla} \nabla \boldsymbol{\nabla}$

4 Lucro estimado pela Organização das Nações Unidas (2012) em U\$320 bilhões ao ano, sendo assim considerada a atividade econômica ilegal mais lucrativa.

5 Lucro de U\$724 bilhões em 2008, segundo dados da IMS Health apresentados pela Fundação Instituto de Pesquisas Econômicas, Administrativas e Contábeis de Minas Gerais (Fundação Instituto de Pesquisa Econômicos, 2011). 
mentação, educação) (Canguilhem, 2009). O desenvolvimento de tecnologias para intervir sobre os aspectos considerados patológicos, desviantes ou indesejáveis permitiu a expansão de um setor econômico altamente lucrativo, atualmente denominado complexo industrial da saúde.

Interessa, para o objeto deste estudo, deter-se na medicalização do sofrimento psíquico e, particularmente, do uso de SPA. Nas últimas décadas, houve uma impressionante proliferação de entidades nosológicas psiquiátricas, acompanhadas/ precedidas da invenção de medicamentos psicotrópicos capazes de curá-las ou ao menos de controlar os sintomas a elas associados. Especificamente em relação ao uso de SPA, cristalizou-se a noção da dependência química como doença, estabeleceu-se a abstinência como meta do tratamento e definiu-se como papel das ciências da saúde nesta área a busca do controle sobre a adicção.

As intervenções terapêuticas são frequentemente definidas com pouca ou nenhuma participação dos sujeitos que fazem uso nocivo de SPA. Nesse tipo de abordagem, infelizmente ainda hegemônica no campo da saúde, os sujeitos são destituídos de seus direitos e responsabilidades, reduzidos à condição de dependentes químicos e culpabilizados pela sua situação. Quando aspectos socioculturais ou elementos da trajetória de vida são considerados, em geral o são em uma perspectiva determinista e estigmatizante, incapaz de apreender a complexidade psicossocial da questão das drogas.

É importante esclarecer que essas concepções e práticas em relação ao uso de SPA não são as únicas presentes nas instituições médicas e entre os profissionais desta categoria; além disso, a crítica não se dirige especificamente aos últimos. $\mathrm{Na}$ formulação de Fiore (2008):

[...] uma sociedade medicalizada, na falta de um outro termo melhor, não é necessariamente aquela em que os médicos e suas prescrições impõem seu poder, na condição de sujeitos, sobre cidadãos leigos sujeitados; trata-se de uma sociabilidade em que os dilemas colocados pelos saberes valores fundamentais e perseguidos continuamente (p.143).

Passa-se, então, à discussão do segundo sustentáculo do proibicionismo, a criminalização. Embora tenham existido leis pontuais referentes à produção, à distribuição e ao consumo de SPA precedentes, sua proibição sistemática, organizada e internacionalmente articulada data do início do século XX. Os Estados Unidos da América foram os principais impulsionadores das legislações internacionais e da criação de leis nacionais de cunho proibicionista. As motivações para a criminalização das substâncias a partir de então denominadas drogas são múltiplas e complexas:

[...] não se 'explica' o empreendimento proibicionista por uma única motivação histórica. Sua realização se deu numa conjunção de fatores, que incluem a radicalização política do puritanismo norte-americano, o interesse da nascente indústria médico-farmacêutica pela monopolização da produção de drogas, os novos conflitos geopolíticos do século XX e o clamor das elites assustadas com a desordem urbana (Fiore, 2012, p.9).

A partir dos anos 1960, o discurso e as práticas repressivas em relação às drogas assumem um caráter belicista. Em 1961, a Convenção Única sobre Entorpecentes da ONU - defendida, patrocinada e sediada pelos Estados Unidos e ratificada por cerca de cem países - lançou as bases legais da política internacional de "guerra às drogas" vigente até os dias atuais. A adoção do modelo bélico para o tratamento de determinadas SPA pode ser explicada por dois fatores principais. Em primeiro lugar, trata-se do período da Guerra Fria, no qual a militarização das relações internacionais e nacionais de cada Estado era interessante para justificar e manter os gastos bilionários com armamentos por parte dos dois blocos antagônicos, liderados pelos Estados Unidos e pela União Soviética. Em segundo lugar, a década de 1960, no mundo ocidental, é a década dos chamados movimentos de contracultura, da ascensão da luta operária, dos movimentos pela independência na África e contra as ditaduras na América Latina. A repressão 
a todos esses movimentos que questionavam o modelo de sociedade vigente também exigia um Estado militarizado. Assim, a "guerra santa contra as drogas" cumpriu um papel fundamental nas relações geopolíticas internacionais e na política interna das nações que a ela aderiram (Silva, 2011).

Nesse período, surgiram ideologias baseadas na noção maniqueísta de "luta do bem contra o mal". Em um contexto de aumento no consumo, principalmente da maconha e de novas drogas sintéticas entre jovens das classes média e alta, a diferenciação conceitual e de tratamento entre "traficantes" e "toxicômanos" ganhou importância. Assim, o pequeno distribuidor de drogas, vindo dos guetos, suposto incitador do consumo, era qualificado como delinquente. Já o consumidor, filho de "boa família", supostamente corrompido pelos traficantes, era qualificado como doente/ dependente, merecedor de tratamento médico e psicológico. Essa construção ideológica também se reproduziu em escala internacional, com a representação dos países "produtores de drogas" (como Colômbia, Bolívia e China) como países-agressores, e dos Estados Unidos e dos países da Europa Ocidental como países-vítimas.

[...] ao exteriorizar o problema, identificando 'fontes' além-fronteiras, o Estado norte-americano pôde apresentar o tema do narcotráfico como uma questão de segurança nacional. [...] o tema do narcotráfico [cresceu] de importância na agenda diplomáticomilitar dos EUA ao longo dos anos 1980, na medida em que diminuía a atenção dada ao 'perigo comunista'. Houve um período de hibridização das ameaças, nas chamadas narco-guerrilhas - como as Forças Armadas Revolucionárias da Colômbia (FARC) e o Sendero Luminoso peruano -, que a partir dos anos 1990 consolidou-se na forma da associação tráfico-terrorismo, hoje muito importante não apenas na política externa estadunidense, mas também nas de seus aliados e nos debates travados nos foros políticos internacionais (Rodrigues, 2008, p.99).
Vale lembrar que toda guerra é uma guerra contra pessoas e que a imensa maioria de suas vítimas são indivíduos oriundos das classes sociais mais pobres e estigmatizadas. No caso da "guerra às drogas", o pretenso combate ao tráfico se concentra no comércio varejista, ocupado por aqueles que obtêm o menor lucro na cadeia internacional do tráfico. Trata-se de sujeitos considerados descartáveis e perigosos para a ordem social estabelecida, que devem ser controlados ou eliminados "porque são, a um só tempo, consumidores imperfeitos (sem capacidade de compra dos bens comercializados) e figuras perigosas (porque pobres, imigrantes, desocupados, marginais)" (Rodrigues, 2008, p.100).

Para um olhar mais atento, são inúmeras as evidências dos reais propósitos da cruzada moral e bélica "contra as drogas". A partir de uma perspectiva de defesa dos direitos humanos, pode-se afirmar que o proibicionismo, além de ser absolutamente ineficaz no que supostamente se propõe a realizar, gera imensos riscos e danos, os quais se distribuem de forma desigual na população.

\section{A implantação do proibicionismo no Brasil}

Conforme apontado acima, a emergência da questão das drogas enquanto problemática merecedora de intervenções por parte do poder público se deu na virada do século XIX para o século $X X$, tendo já nascido como uma política internacional. No Brasil, trata-se do período de formação do Estado burguês e de transição da formação social brasileira para o modo de produção capitalista (Saes, 2006). Isso significa um processo acelerado de urbanização e industrialização, acompanhado de condições miseráveis de trabalho e de existência para a maior parte da população. Assim, o início do século XX foi marcado pelas rebeliões urbanas dos afrodescendentes e por outras lutas sociais ameaçadoras ao estabelecimento de uma nova ordem.

A tensão entre as classes que se consolidavam produziu o que, desde então, vem sendo denominado como questão social, expressão que abarca diversas manifestações de um complexo 
fenômeno político, econômico e cultural. A questão social foi tratada, durante a Primeira República Brasileira (1889-1930), com um amplo espectro de medidas, as quais englobam desde a embrionária política de regulamentação do mercado de trabalho até o reforço das ações policiais repressivas, passando, no campo das políticas de saúde, por práticas higienistas, que articulam intervenções de cunho sanitário e social/moral.

É nesse contexto que se deve situar a emergente "questão das drogas". Diante da necessidade de conter essa ameaça e de formar uma classe trabalhadora constituída de indivíduos saudáveis e dóceis, o combate ao uso de determinadas SPA (ou a determinadas formas de uso das mesmas, como no caso do álcool) foi uma das estratégias de enfrentamento da luta das classes populares insatisfeitas com suas condições de existência.

Dentre as diversas SPA consumidas no Brasil nesse período, a cachaça e a maconha tornaram-se alvos dos discursos médico-científicos e jurídico-criminais que legitimavam a repressão política, a depreciação social e a desqualificação moral de grupos sociais subalternos. Essas duas substâncias têm papel de destaque no engendramento de uma sensibilidade social peculiar, historicamente construída, a qual modula as percepções e enquadramentos que essa problemática recebe culturalmente. Nesse sentido,

[...] o 'crackeiro' seria apenas o sucessor, na linha evolutiva das substâncias vitimadoras, do 'cachaceiro' e do 'maconheiro', que the antecederam nessa história de violência e dominação, na qual a miséria econômica, associada à marca de raça e de classe, antecipa o risco do desenvolvimento da miséria moral, condição de uma desqualificação plena daqueles indivíduos que não foram 'fortes o bastante', 'resilientes' e 'sucumbiram ao mal' (Conselho Federal de Psicologia, 2013a, p.24).

Assim, as políticas proibicionistas que passaram a ser implantadas globalmente no início do século XX encontraram em nosso país um campo fértil, do ponto de vista da representação social do uso de SPA. De fato, o paradigma proibicionista contou não apenas com a aprovação das elites nacionais que ocupavam o poder, mas com a participação ativa dessas elites em sua formulação nos fóruns internacionais.

\section{As políticas de álcool e outras drogas no Brasil}

Não será possível, no âmbito deste artigo, abordar em detalhes os desdobramentos da medicalização e da criminalização da questão das drogas no Brasil do início do século XX até os dias atuais. No entanto, uma análise fundamental a ser realizada a respeito desses processos é que estão profundamente imbricados e se configuram, dialeticamente, como produtos e produtores de uma ordem social a qual necessita renovar constantemente suas formas de controle.

\section{Um balanço dos mortos e feridos na "guerra às drogas"}

A configuração atual das políticas de álcool e drogas no Brasil foi engendrada na década de 1960, quando, conforme discutido no primeiro item, o paradigma proibicionista passa a se revestir de um discurso e a atuar segundo uma lógica declaradamente belicista. Às três dimensões de periculosidade associadas às drogas desde o início do século XX (a moral, a saúde e a segurança pública), somaram-se então as da segurança nacional e internacional, tornando "o tema do tráfico de drogas não apenas ... um problema de segurança doméstica ou de um Estado, mas um perigo associado a uma ameaça à 'ordem mundial' " (Rodrigues, 2008, p.100).

O marco legal que inaugura a política de "guerra às drogas" - a supracitada Convenção Única sobre Entorpecentes da ONU, de 1961 - foi promulgada pelo governo brasileiro em 1964, já sob a ditadura militar e a doutrina da segurança nacional. Além da adesão à radicalização estadunidense no plano internacional, houve um endurecimento das leis "antidrogas" brasileiras durante a ditadura (1964-1985). 
Os efeitos mais dramáticos da "guerra às drogas" no Brasil são o extermínio e o encarceramento em massa da população jovem, pobre e negra (em sua maioria), conforme os dados que serão apresentados a seguir. Rodrigues (2008) usa a expressão "confinamentos ampliados" para se referir ao fato de que o próprio território de vida desses sujeitos, que também é o de atuação do tráfico, é uma prisão (as favelas, os morros, as periferias dos grandes centros urbanos). Para esse autor, a guerra às drogas se configura como uma "potente tática de controle social e perseguição seletiva" (p.102).

Os dados do "Mapa da Violência 2013: homicídio e juventude no Brasil" (Waiselfisz, 2013) são alarmantes: entre 1980 e 2011, o homicídio de jovens cresceu 326,1\%; dos 467,7 mil homicídios contabilizados entre 2002 e 2010, 307,6 mil $(65,8 \%)$ foram de negros; nesse mesmo período (2002-2010), houve decréscimo de 26,4\% nos casos de homicídios de brancos e acréscimo de $30,6 \%$ nos de negros.

Os dados do sistema prisional não são mais animadores, como demonstram informações do Ministério da Justiça do Brasil e do International Centre for Prison Studies, citados por Karam (2013). Nos últimos vinte anos, o Brasil praticamente quadruplicou sua população carcerária - atualmente a quarta maior no mundo. Em dezembro de 2012, havia 548003 presidiários no país, o que corresponde a 287,31 presos por cem mil habitantes (a média mundial, segundo dados de maio de 2011, é de 146 por cem mil habitantes). Em dezembro de 2005, os acusados e condenados por tráfico de drogas representavam 9,10\% do total dos presos brasileiros; em dezembro de 2012, chegavam a 26,90\%; entre as mulheres, o que alcança praticamente metade das presas (47,35\%), tendo chegado a quase $60,00 \%$ no ano anterior (em dezembro de 2011, eram 57,62\%).

\section{As políticas de saúde e suas contradições}

No campo da saúde, herdou-se da ditadura civil-militar uma radicalização do modelo estruturado pela lógica dos negócios, através do incentivo estatal para construir e equipar hospitais privados e de um alto grau de incorporação tecnológica (Cardoso, 2013). Para a política de saúde mental, esse modelo se traduziu na multiplicação das internações psiquiátricas, com a assistência centrada na prescrição de drogas psicotrópicas, cuja disponibilidade no mercado cresceu vertiginosamente a partir da metade da década de 1950, aumentando de forma espetacular a capacidade de intervenção terapêutica da Psiquiatria e dando um novo impulso ao processo de medicalização das mais diversas dimensões da vida. Assim, floresceu, no período da ditadura civil-militar, a chamada "indústria da loucura", que chegou a abrigar, no final dos anos 1980, cerca de 100 mil leitos distribuídos em 313 hospitais psiquiátricos, sendo $20 \%$ públicos e $80 \%$ privados, concentrados principalmente no Rio de Janeiro, em São Paulo e em Minas Gerais (Conselho Federal Psicologia, 2013b, p.53).

Mas é fundamental lembrar que, em meados do século XX (sob influência da experiência traumática da Segunda Guerra Mundial, entre outras), também foram elaboradas em diversas partes do mundo críticas mais sistemáticas ao modelo manicomial e à grave violação de direitos humanos nele perpetrada. Surgiram novas propostas terapêuticas, inclusive no Brasil, construídas de forma pontual em alguns serviços, merecendo destaque os trabalhos de Ulysses Pernambuco (1892-1943) em Recife e de Nise da Silveira (1905-1999) no hospital de Engenho de Dentro, no Rio de Janeiro. Para além da saúde mental, intensificou-se a crítica à forma de organização da assistência à saúde no país, ainda determinada pela divisão entre a saúde pública, com seu modelo higienista, e a atenção médica previdenciária, de cunho curativista e privado.

Eis o cenário político e social de emergência dos movimentos da Luta Antimanicomial, das Reformas Sanitária e Psiquiátrica e Antiproibicionista que alcançaram grande visibilidade e legitimidade no final da década de 1970. A compreensão das condições gerais de vida - como moradia, alimentação, saneamento básico, condições de trabalho, educação e lazer -, enquanto determinantes da saúde individual e coletiva oferecia 
a base política para a articulação com outros movimentos sociais em processo de (re)organização no período.

Já no final dos anos 1970 e início dos anos 1980, surgiram propostas e experiências concretas de mudança no modelo de atenção à saúde no Brasil que não estavam isoladas dos debates internacionais. A VIII Conferência Nacional de Saúde, realizada em 1986, com o tema "Democracia é Saúde", foi o marco político decisivo para a construção do Sistema Único de Saúde (SUS). Na ocasião, a saúde foi afirmada como direito humano fundamental e discutiu-se a forma de organização e as bases de financiamento do novo modelo. A incorporação da saúde como direito de todos e dever do Estado na Constituição Federal de 1988 foi uma vitória importante para o movimento nos campos político e legal.

No campo da saúde mental, até metade da década de 1980, o foco da luta esteve voltado à denúncia das péssimas condições a que estavam submetidos os sujeitos internados em manicômios. No entanto, diante da constatação da insuficiência dessa estratégia e sob a influência das discussões no campo da saúde como um todo e dos processos de reforma psiquiátrica em curso em diversos países (particularmente da Psiquiatria Democrática italiana), houve uma radicalização do movimento. Seguindo a palavra de ordem que se tornou emblemática - "Por uma sociedade sem manicômios!" -, já não se tratava de humanizar o tratamento nas instituições psiquiátricas existentes, mas de questionar os próprios fundamentos filosóficos e a função social da Psiquiatria, dos quais a violência institucionalizada é consequência.

A tradução dessa proposta em termos de política pública consiste na substituição progressiva das instituições psiquiátricas tradicionais por serviços comunitários de saúde mental, articulados em uma ampla rede intersetorial produtora de vida, de sentido e de sociabilidade (Rotelli, 1990). Assim, dentro dos marcos da construção do SUS, teve início um processo de redução de leitos em hospitais psiquiátricos e de estruturação de uma rede de atenção psicossocial substitutiva, orientada pelos princípios da territorialidade, do vínculo entre usuários e equipes multiprofissionais, da promoção de autonomia e da participação social.

Além da melhora das condições de vida concretas, essas propostas implicam profundas mudanças culturais. Somam-se a esses enormes desafiosas contradições intrínsecas à construção de uma política social de caráter público, que busca garantir direitos humanos fundamentais a uma população à qual os mesmos foram repetidamente negados, em um momento histórico de avanço e consolidação do projeto neoliberal.

Apesar das condições desfavoráveis e considerando inúmeros limites e contradições, é possível afirmar que foi estruturado um sistema público de saúde no Brasil, articulado a uma rede de cuidados em saúde mental cuja composição transcende a área da saúde. Com a promulgação da Lei n¹0.216 e a realização da III Conferência Nacional de Saúde Mental em 2001, houve um novo impulso e uma aceleração do processo da Reforma Psiquiátrica, com uma expansão significativa da rede de atenção psicossocial (Ministério da Saúde, 2012).

A criação de novos dispositivos e a inserção das ações de saúde mental em uma rede de serviços de caráter interdisciplinar permitem novas abordagens a pessoas em situação de sofrimento psíquico atualmente. No entanto, a implementação dessas políticas não garante a mudança paradigmática do modelo de atenção à saúde mental. As experiências transformadoras do cuidado ainda convivem com a institucionalização (em serviços públicos, conveniados ou privados, tanto novos quanto antigos) e com suas práticas centradas no intervencionismo diagnóstico e terapêutico.

Há que se reconhecer ainda o atraso de uma década (em relação às conquistas destinadas aos portadores de transtornos mentais gerais) na implantação de políticas que respaldassem as ações de saúde pautadas pelo respeito à autonomia e pela defesa dos direitos dos usuários de SPA. Somente em 2003 o Ministério da Saúde apresentou sua Política de Atenção Integral a Usuários de Álcool e outras Drogas, orientada pela perspectiva e pelas práticas da Redução de Danos. Entretanto, a mesma política nacional incorporou abordagens 
extremamente contraditórias com base nessa orientação, como o financiamento estatal de comunidades terapêuticas - instituições cujas práticas se opõem aos princípios e diretrizes do SUS e da Reforma Psiquiátrica.

As principais características dessas instituições são a prática de internação prolongada, o isolamento e o forte componente religioso que orienta as suas práticas, além da inexistência de um projeto terapêutico singular, institucional e educacional, que incentive a autonomia e participação das pessoas que estão na condição de internos. [...] algumas dessas instituições incluem em suas práticas o uso excessivo de psicofármacos, evidenciando a pobreza de outros recursos terapêuticos e clínicos. As comunidades terapêuticas, que defendem o paradigma da abstinência, reproduzem práticas sociais com características disciplinares e normalizadoras próprias dos espaços prisionais e manicomiais (Conselho Federal de Psicologia, 2013a, p.33).

\section{A Redução de Danos como paradigma alternativo ao proibicionismo}

Sem dúvida, as consequências mais nefastas do proibicionismo se situam no âmbito da produção e da comercialização de SPA ilícitas, englobando, além dos homicídios e do encarceramento em massa, práticas como a corrupção de agentes públicos e a exploração do trabalho (inclusive infantil). Mas elas também se manifestam no âmbito do consumo.

Primeiramente, a criminalização expõe os consumidores de drogas ilegais a riscos para a obtenção e uso das mesmas, através da forçosa relação com o tráfico e da possibilidade de repressão e extorsão pelos agentes de segurança pública. Uma das decorrências de um marco regulatório tão simplório que divide a enorme diversidade de SPA em um esquema binário (permitidas e proibidas) é que "duas drogas tão diferentes como maconha e cocaína, por exemplo, misturam-se não só no imaginário, mas nos locais e/ou nas pessoas que as vendem" (Fiore, 2012, p.16).
Outro aspecto negativo do modelo proibicionista para os consumidores é a ausência de controle sobre a qualidade das drogas ilegais. Ao contrário do que acontece com o álcool ou com os medicamentos psicotrópicos, por exemplo, ao consumir drogas ilegais, ignora-se o que e quanto se está consumindo. As consequências vão desde o efeito insatisfatório da substância até as overdoses, passando por efeitos colaterais mais ou menos graves. A enorme variabilidade na composição das drogas ilegais também dificulta o fornecimento de informações sobre formas de uso mais seguras e a promoção do autocuidado.

Em um artigo que resgata as formulações de diversos pesquisadores sobre os aspectos socioculturais do uso de drogas, MacRae (s.d.) afirma que, apesar da ampla difusão da ideia de que o consumo de substâncias psicoativas (lícitas ou ilícitas) é regido pelo caos e pela loucura, ele raramente ocorre de maneira desregulada. Há rituais e controles sociais formais e informais específicos para o consumo de cada SPA, em cada contexto sociocultural, que se aplicam "aos métodos de aquisição e administração da substância, à seleção do meio físico e social para usá-la, às atividades empreendidas após o uso, e às maneiras de evitar efeitos indesejados" (p.2). Esses controles sociais existem em várias dimensões, desde grupos específicos até âmbitos culturais mais amplos, e são flexíveis (como demonstra a suspensão das sanções sociais em relação ao uso de inalantes durante o carnaval no Brasil).

O autor também faz referência aos trabalhos sobre toxicomania desenvolvidos por Robert Castel e Anne Coppel, que apontam três instâncias de regulação: os heterocontroles, representados por leis, instituições de saúde etc.; os controles societários, como pressões informais de pares e vizinhos; e os autocontroles, que seriam os "variados graus de controle que os próprios usuários são capazes de exercer sobre suas práticas de consumo", sendomuitas vezes "internalizações dos controles societários e legais" (MacRae, s.d., p.3). Na visão dos autores citados, enquanto a ação dos heterocontroles "é pontual e restrita a certas situações, os controles societários seriam muito mais eficazes por se exercerem de maneira 
permanente através das redes de sociabilidade" (MacRae, s.d., p.3).

Em resumo, pode-se dizer que a política de redução de danos relacionados ao uso de drogas preconiza a valorização do autocuidado e dos controles sociais desenvolvidos nas redes de sociabilidade dos próprios usuários. Essa abordagem implica uma postura aberta, respeitosa e participativa, que tem se mostrado muito mais eficaz em limitar os efeitos indesejáveis do uso de SPA (inclusive das legalizadas) do que o proibicionismo.

\section{Considerações Finais}

Olhar para o panorama atual da questão das drogas a partir de suas raízes históricas, compreendendo os interesses políticos, econômicos e sociais que levaram à sua constituição, significa também explicitar a hipocrisia e as distorções presentes nos discursos médicos, jurídicos, religiosos, científicos e midiáticos hegemônicos. Rodrigues (2008) faz uma boa síntese dos elementos mobilizados na "guerra às drogas", os quais possibilitam o alcance de seus objetivos não declarados e a tornam, afinal, vitoriosa:

Nesse sentido, não se quer afirmar que o proibicionismo seja a única, ou mesmo a mais importante, técnica de assédio e aprisionamento destinado às 'classes perigosas', mas que ele é um importante recurso nessa função global de disciplina e contenção. Cada crime produzido por novas legislações inaugura um novo flanco de combate aos 'perigosos', um novo acesso ao sistema penitenciário, uma outra entrada para a vigilância constante. Se existe um crime que é forjado com tamanha carga de reprovação moral e científica, temos à frente um 'perigo' de considerável importância que conquista e catalisa sem dificuldades o consenso repressivo das sociedades. O 'fracasso' da proibição, então, potencializa-se em positividade: a guerra perdida contra 'as drogas' significa a guerra diariamente renovada e eficaz contra pobres, imigrantes, negros, camponeses entre outros 'ameaçadores' (Rodrigues, 2008, p.98).
Apesar do cenário desfavorável, multiplicaram-se, nos últimos anos, organizações políticas que assumiram o antiproibicionismo como pauta central. Essa discussão também vem sendo progressivamente incorporada na agenda de lutas de diversos movimentos sociais. As iniciativas antiproibicionistas estão articuladas em redes internacionais e têm ocupado espaço na mídia, nas ruas, nas universidades e no próprio Estado. Vozes dissonantes têm-se tornado audíveis, ainda que muito pontualmente, em cargos de gestão pública, no Poder Judiciário, em mandatos legislativos, fóruns democráticos nacionais e internacionais; e com maior capilaridade em alguns serviços de assistência social, de saúde e do sistema jurídico-penal que atendem diretamente a população afetada (de múltiplas formas) pela "questão das drogas".

As reflexões e propostas apresentadas por esses atores demonstram que a defesa de um modelo alternativo ao proibicionismo não significa negar os problemas associados ao consumo de SPA em nossa sociedade, nem a necessidade de construção de políticas públicas para abordá-los (acusações frequentemente levantadas na tentativa de desqualificar o movimento antiproibicionista). Significa precisamente rediscutir o papel do Estado, de forma que suas ações contribuam de fato para a redução de danos e para a promoção de autonomia - que pressupõe co-responsabilização e garantia de direitos humanos. Do contrário, a sociedade seguirá criando seus próprios demônios:

Com a repetição de ideias falseadas, autoritárias e preconceituosas, tem-se operado uma desqualificação e demonização do usuário e do 'traficante' (também tratado de maneira pouco matizada). O reducionismo dessa estereotipação, ao encobrir alguns dos reais problemas estruturais da sociedade, criando um inimigo imaginário que tem sua utilidade na manutenção do status quo, acaba por aumentar a marginalização dos usuários, assim como leva à cristalização uma 'subcultura da droga' de pouca permeabilidade a agentes de saúde ou a representantes de qualquer tipo de discurso oficial. E, como uma profecia que cumpre a si mesma, isso leva à criação de novas 
ameaças à ordem e à saúde nessa sociedade (MacRae, s.d., p.1).

Na versão "bem-intencionada" dessa perspectiva maniqueísta, não são os sujeitos, mas as próprias SPA (substâncias inertes, vale lembrar) que são culpabilizadas pelo mal-estar social que seu uso nocivo explicita. Essa inversão da relação sujeito/ objeto, afirmando as SPA como inerentemente "más", desconsiderando o(s) sujeito(s) e os contextos socioculturais de uso, serve à legitimação do proibicionismo e ao velamento das relações sociais historicamente estabelecidas, cuja violência as famigeradas "cracolândias" - apesar de todos os esforços em contrário - escancaram.

\section{Colaboradores}

L.N. RYBKA foi responsável pela concepção e pelo desenho do artigo, bem como pela análise do material de campo. J.L. NASCIMENTO foi orientadora da referida pesquisa, auxiliando em todo o processo de escrita do artigo, bem como na produção e revisão do produto final. R.S.L GUZZO compôs as bancas de qualificação e de defesa da pesquisa, contribuindo principalmente com a elaboração do referencial teórico-metodológico.

\section{Referências}

Canguilhem, G. (2009). O normal e o patológico (6a ed.). Rio de Janeiro: Forense Universitária.

Cardoso, F. M. (2013). A saúde entre os negócios e a questão social: privatização, modernização e segregação na ditadura civil-militar (1964-1985) (Dissertação não-publicado). Universidade Estadual de Campinas.

Conselho Federal de Psicologia. (2013a). Referências técnicas para a atuação de psicólogas/os em políticas públicas de álcool e outras drogas. Brasília: Autor.

Conselho Federal de Psicologia. (2013b). Referências técnicas para atuação de psicólogas(os) no CAPS - Centro de Atenção Psicossocial. Brasília: Autor.

Donnangelo, M. C. F. (1975). Medicina e sociedade: o médico e seu mercado de trabalho. São Paulo: Pioneira.
Duarte, P. C. A. V., Stempliuk, V. A., \& Barroso, L. P. (Orgs.). (2009). Relatório brasileiro sobre drogas. Brasília: Secretaria Nacional de Políticas sobre Drogas.

Escohotado, A. (1998). Historiageneral de las drogas. Madrid: Espasa Calpe.

Fiore, M. (2008). Prazer e risco: uma discussão a respeito dos saberes médicos sobre uso de "drogas". In B. C. Labate, S. Goulart, M. Fiore, E. MacRae, \& H. Carneiro (Orgs.), Drogas e cultura: novas perspectivas (pp. 141-153). Salvador: EDUFBA.

Fiore, M. (2012). O lugar do Estado na questão das drogas: o paradigma proibicionista e as alternativas. Novos Estudos CEBRAP, 92, 9-21.

Karam, M. L. (2009). Proibições, riscos, danos e enganos: as drogas tornadas ilícitas. Rio de Janeiro: Lumen Juris.

Karam, M. L. (2013). Proibição às drogas e violação a direitos fundamentais. In Law Enforcement Against Prohibition - LEAP Brasil. Recuperado em agosto 3, 2014, de http://www.leapbrasil.com.br/textos

MacRae, E. (s.d.). Aspectos socioculturais do uso de drogas e políticas de redução de danos. São Paulo: Núcleo de Estudos Interdisciplinares sobre Psicoativos. Recuperado em junho 20, 2014, de http://www.neip. info/downloads/edward2.pdf

Ministério da Saúde (Brasil). (2012). Coordenação Geral de Saúde Mental, Álcool e Outras Drogas. Saúde Mental em Dados - 10. (Informativo eletrônico de dados sobre a Política Nacional de Saúde Mental). Brasília: Ministério da Saúde. Recuperado em julho 15, 2014, de www.saude.gov.br/bvs/saudemental

Rodrigues, T. (2008). Tráfico, guerra, proibição. In B. C. Labate, S. Goulart, M. Fiore, E. MacRae, \& H. Carneiro (Orgs.), Drogas e cultura: novas perspectivas (pp. 91-104). Salvador: EDUFBA.

Rotelli, F. (1990). A instituição inventada. In M. F. S. Nicácio (Org.), Desinstitucionalização (pp. 89-100). São Paulo: Hucitec.

Saes, D. A. M. (2006). Direitos sociais e transição para o capitalismo: o caso da Primeira República Brasileira (1889-1930). Estudos de Sociologia, 11(20), 23-51.

Silva, A. F. L. M. (2011). Histórico das drogas na legislação brasileira e nas convenções internacionais. Revista Jus Navigandi, 16(2934). Recuperado em maio 10, 2014, de http://jus.com.br/artigos/19551

Waiselfisz, J. J. (2013). Mapa da violência 2013: homicídios e juventude no Brasil. Brasília: Secretaria Geral da Presidência da República.

Recebido: outubro 29, 2015

Versão final: dezembro 19, 2016

Aprovado: janeiro 26, 2017 